Universidade Tecnológica Federal do Paraná - UTFPR

Campus Ponta Grossa - Paraná - Brasil

ISSN: (em solicitação)/ v. 01, n. 01: p. 64-81, 2007
Revista Brasileira de Tecnologia

Agroindustrial

\title{
OPTIMIZAÇÃO DO RENDIMENTO DO SUMO DE CENOURA DURANTE O PROCESSO PRODUTIVO
}

\section{CARROT JUICE YIELD OPTIMIZATION IN THE PRODUCTION PROCESS}

\author{
Luis Santiago Calvo Fariña ${ }^{1}$; Ivo Manuel Mira Abreu Rodrigues ${ }^{2}$; Marta Helena Fernandes Henriques ${ }^{3}$, Rui \\ Jorge Lima Saraiva ${ }^{4}$ \\ ${ }^{1}$ Escuela Técnica Superior de Ingenierías Agrarias de Palência - Palência - Espanha demiurgo1977@hotmail.com \\ ${ }^{2}$ Escola Superior Agrária de Coimbra - IPC - Coimbra - Portugal mhenriques@esac.pt \\ ${ }^{3}$ Escola Superior Agrária de Coimbra - IPC - Coimbra - Portugal ivorod@esac.pt \\ ${ }^{4}$ Escola Superior Agrária de Coimbra - IPC - Coimbra - Portugal rsaraiva@esac.pt
}

\section{Resumo}

Nos últimos anos tem-se verificado uma clara tendência do consumo de sumos de fruta pela sua incorporação na dieta dos consumidores, substituindo por sua vez a fruta e os refrigerantes. Pelas suas características vitamínica e antioxidante, o sumo de cenoura tem sido progressivamente introduzido na formulação dos sumos de fruta; o principal problema da sua utilização é o baixo rendimento durante o processo produtivo e as questões que se prendem com a sua estabilização química e microbiológica. Este trabalho teve como objectivo a optimização do rendimento em sumo de cenoura durante o seu processo produtivo. Os factores testados foram o tempo da operação de escaldão $(60,90,120,150$ s) e a adição de diferentes enzimas (pectinase, $\alpha$-amilase e celulase) durante o processo de trituração. Para além do rendimento em sumo, foi também avaliada a influência que os tratamentos térmicos tiveram no pH, ${ }^{\circ}$ Brix, acidez e cor do sumo produzido. Efectuaram-se análises microbiológicas para a avaliação da esterilidade comercial do sumo embalado. O aumento tempo de escaldão prejudica o rendimento global do processo, principalmente porque diminui a rendimento da operação de prensagem. Verificou-se um aumento do rendimento da extracção do sumo de cenoura pela adição de enzimas, nomeadamente com a utilização da pectinase. Esta enzima permitiu um aumento de rendimento de $20 \%$ relativamente ao caso padrão, sem a utilização de enzimas. A utilização da celulase contribui para um aumento do conteúdo em sólidos solúveis (12 ${ }^{\circ}$ Brix) e \% acidez $(0,055 \%(p / p))$. A estabilidade microbiológica foi conseguida por esterilização em autoclave.

Palavras-chave: sumo de cenoura, rendimento, escaldão, tratamento enzimático, esterilização

\section{Introdução}

A indústria alimentar moderna está orientada para o desenvolvimento de novos produtos no sentido de fazer face às necessidades crescentes dos consumidores. A tendência, para a crescente incorporação de sumos de fruta na dieta humana como substituto da fruta, das bebidas carbonatadas 
e dos refrigerantes, associada aos benefícios de algumas das suas substâncias, leva o consumidor a aumentar a procura de novos produtos com características semelhantes às encontradas nos sumos à base de cenoura. De alguns anos a esta parte, o sumo de cenoura tem vindo a ser incorporado como elemento de mistura na elaboração de sumos de fruta, em concentrações variáveis, mas sempre como elemento secundário. O consumidor, mais informado acerca dos alimentos que consome, associado a uma rotulagem mais completa e rigorosa, valoriza cada vez mais as propriedades nutricionais do sumo de cenoura (Tabela 1), tendo como consequência a crescente procura de alimentos que o tenham na sua composição. O sumo de cenoura apresenta propriedades anticépticas e reguladoras da corrente sanguínea. É também recomendado para combater as doenças oftalmológicas, o reumatismo, a anemia, a impotência sexual e doenças respiratórias (Chen et al., 1996).

Na produção dos sumos de fruta a qualidade e quantidade dos componentes específicos da matéria-prima são essenciais no custo de produção e valor nutritivo do produto final. O componente em maior abundância na cenoura é a água (88,1-91,9\%). As restantes substâncias são praticamente: açúcares simples e complexos (glucose, frutose, sacarose, amido, substâncias pécticas e celulose), vitaminas, ácidos orgânicos, azoto e compostos minerais, lípidos e taninos (Zadernowski et al., 2003). Os açúcares solúveis são os responsáveis por conferir o sabor doce ao sumo e encontram-se na matéria-prima numa concentração entre 5,35-8,1\%, dos quais 2-3\% correspondem à sacarose e 0,39-0,91\% dizem respeito ao amido. A proporção entre os ácidos orgânicos e os açúcares presentes na cenoura é bastante baixa, traduzindo-se num elevado valor de $\mathrm{pH}$. Consequentemente a acidez total varia entre $0,13-0,99 \mathrm{~g} / 100 \mathrm{~g}$ (base húmida). Este factor é limitante na conservação do sumo de cenoura, implicando tratamentos térmicos ou químicos com a adição de ácidos (cítrico e/ou ascórbico). As cenouras são uma boa fonte de fibras particularmente de pectinas e celulose (1,012,44\% (base húmida).

O elemento mais característico da sua composição é, sem dúvida, o $\beta$-caroteno que representa $45-70 \%$ dos carotenoides totais. É o precursor da vitamina A e responsável por uma grande variedade de efeitos benéficos para a saúde humana. Diversos estudos científicos demonstraram que a probabilidade de ataques cardíacos se reduz por ingestão deste nutriente. É um antioxidante lipossolúvel que neutraliza os radicais livres, combinando-se directamente com eles, o que aumenta a eficácia do sistema imunitário. $\mathrm{O}$ uso do $\beta$-caroteno foi proposto como tratamento para combater algumas doenças como o alcoolismo, asma, depressão, epilepsia, esterilidade masculina e feminina, Parkinson, artrites e esquizofrenia. A carência de $\beta$-caroteno provoca uma regressão patológica do olho que pode desencadear uma xeroftalmia e, em casos extremos, cegueira (Coultate, 1986). 
Tabela 1 - Composição nutricional de $100 \mathrm{~g}$ de cenoura fresca. (Adaptado de USDA, 2006; Zadernowski et al., 2003)

\begin{tabular}{ccc}
\hline Componente & Quantidade & Unidade \\
\hline Calorias & 43,00 & $\mathrm{Kcal}$ \\
Lípidos & 0,19 & $\mathrm{~g}$ \\
Hidratos de carbono & $5,35-8,10$ & $\mathrm{~g}$ \\
Amido & $0,39-0,91$ & $\mathrm{~g}$ \\
Pectina total & $0,68-2,45$ & $\mathrm{~g}$ \\
Fibras & $1,01-2,44$ & $\mathrm{~g}$ \\
Celulose & $0,80-1,88$ & $\mathrm{~g}$ \\
Proteínas & 1,03 & $\mathrm{~g}$ \\
Sódio & 35,00 & $\mathrm{mg}$ \\
Potássio & 323,00 & $\mathrm{mg}$ \\
Cálcio & 27,00 & $\mathrm{mg}$ \\
Ferro & 0,50 & $\mathrm{mg}$ \\
Zinco & 0,20 & $\mathrm{mg}$ \\
Vitamina A & 12000 & $\mathrm{UI}$ \\
\hline
\end{tabular}

Uma competição bastante vincada na indústria de sumos de fruta leva a que este tipo de actividade produtiva se preocupe, não só pela grande variedade de produtos que pode oferecer ao consumidor, mas também pelo aumento da qualidade dos mesmos. No entanto, durante o processo produtivo ocorrem significativas perdas e alterações de componentes essenciais responsáveis pela boa cotação dos benefícios nutricionais dos sumos. Embora a incorporação de vitaminas e antioxidantes aos sumos depois de passarem pelo seu processo produtivo seja prática corrente, está provado que não são tão eficazes como os que estariam presentes inicialmente na matéria-prima (Zadernowski et al., 2003). De forma a preservar os componentes de valor acrescentado presentes na matéria-prima utilizada, o processo produtivo terá de ser repensado e optimizado, evitando operações que os degradem, criando condições de processamento que as tornem mais suaves. As operações que mais contribuem para a degradação desses componentes são a trituração, prensagem, tratamentos térmicos e estabilização.

$\mathrm{Na}$ produção dos sumos de cenoura a operação que tem merecido maior atenção é o tratamento térmico, denominado por escaldão. As alterações sofridas na estrutura das paredes celulares durante este tratamento, conduzem a uma degradação dos compostos mais sensíveis à temperatura nomeadamente carotenoides e vitaminas. Alguns estudos mostram que alterações dos parâmetros operacionais durante esta etapa conduzem a alterações do produto final nas características físicas, sensoriais e químicas, tais como a textura, consistência, cor, composição em vitaminas, mono e oligossacarídeos, ácidos, pectinas e fibras (Reiter et al., 2003; Borowska et al., 2006).

Figura 1 - Diagrama de fabrico do sumo de cenoura 


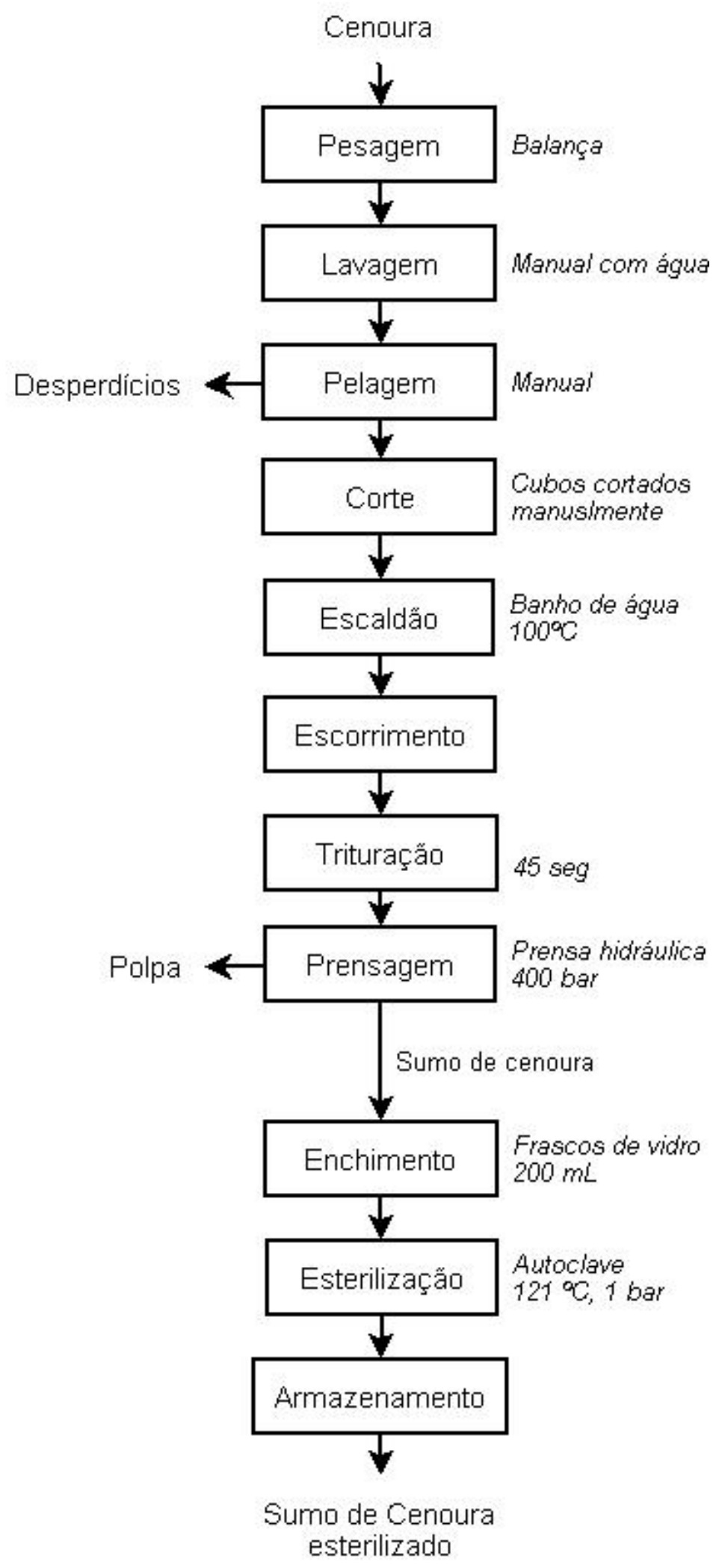

Outra forma de tornar o processo produtivo menos severo é a incorporação de preparações enzimáticas pectolíticas e/ou por vezes celulósicas. O uso de enzimas tem-se revelado muito promissor em termos de rendimento em sumo, proporcionando uma melhor utilização da matériaprima, aumentando a eficiência nas operações unitárias do processo produtivo, no consumo 
energético e, em termos ambientais, reduzindo os desperdícios produzidos (Vora et al., 1999; Zadernowski et al., 2003; Sun et al., 2006). Há que ter em conta que a utilização de enzimas implica a garantia de condições de $\mathrm{pH}$ e temperatura óptimas para a sua actuação. Caso isto se não verifique, os resultados podem ser escassos ou mesmo piores. Alguns autores afirmam que sem o uso de enzimas, não é possível tornar a produção de sumos de alguns frutos e vegetais viável (Helbig e Laperche, 2001). A escolha destas enzimas requer uma elevada precisão, uma vez que a actividade enzimática pode também ser responsável por alterações indesejáveis na cor, sabor, etc.

Este trabalho teve como objectivo a optimização do rendimento do sumo de cenoura ao longo do processo produtivo esquematizado na Figura 1.

Os factores avaliados foram o tempo da operação unitária da escaldão, assim como a adição de diferentes enzimas (pectinase, $\alpha$-amilase e celulase) durante o processo de trituração. Foi também avaliada a influência que os tratamentos térmicos tiveram no $\mathrm{pH}$, ${ }^{\circ}$ Brix, acidez e cor do sumo produzido. Efectuaram-se análises microbiológicas para a avaliação da esterilidade comercial do sumo embalado que esteve sujeito a um tratamento térmico em autoclave a $121^{\circ} \mathrm{C}$.

\section{Materiais e métodos}

\subsection{Materiais e equipamentos}

A matéria-prima usada neste trabalho foi a cenoura Danucus carota L., que pertence à família Apiácia Umbilifera, com as seguintes características:

- Tamanho: 6-9 cm

- Formato: secção transversal circular, cilíndrica

- Variedade: Nantes

- Cor: laranja intenso

- Categoria: II

- Cultivada na região do Ribatejo (Portugal)

Enzimas

- Pectinase Ultrazym 100 G (Novo Nordisk A/S, Denmark)

- Celulase Celluclast (NCBE Enzymes, Novozymes, Reading)

- $\alpha$-amilase Termamyl (NCBE Enzymes, Novozymes, Reading) 
O processo produtivo de sumo de cenoura foi efectuado na instalação piloto da Oficina Tecnológica de Produtos Horto-frutícolas da Escola Superior Agrária de Coimbra.

\subsection{Métodos}

Determinação do rendimento:

A determinação do rendimento individual de cada operação do processo foi efectuada por gravimetria entre a matéria-prima utilizada e o produto final obtido. Foi também determinado o rendimento global do processo com base nos rendimentos individuais de cada uma das operações.

Determinação dos sólidos solúveis:

A medição dos sólidos solúveis foi expressa em ${ }^{\circ}$ Brix e foi realizada com um refractómetro ATAGO 0-30 ${ }^{\circ}$ Brix (Japão). A alteração da densidade do sumo devido à temperatura reveste de extrema importância o controlo deste parâmetro na leitura do ${ }^{\circ}$ Brix do sumo. O refractómetro usado está calibrado para uma temperatura de $20^{\circ} \mathrm{C}$. Caso a amostra analisada não esteja a $20{ }^{\circ} \mathrm{C}$ é necessário corrigir o valor do ${ }^{\circ}$ Brix para a temperatura usada $\left(1^{\circ}\right.$ Brix $\Leftrightarrow 1 \mathrm{~g}$ sólidos solúveis/ $100 \mathrm{~g}$ de solução).

Determinação do $\mathrm{pH}$ :

A medição do valor de $\mathrm{pH}$ foi efectuada num potenciómetro Crison, MicropH 2002 (Espanha), previamente calibrado para o $\mathrm{pH}=4$ e $\mathrm{pH}=7$. A amostra deve ser previamente desgaseificada por agitação magnética.

Determinação da acidez titulável:

A determinação da acidez titulável foi efectuada por um método pontenciométrico com a adição de solução aferida de $\mathrm{NaOH}(0,1 \mathrm{~N})$. A acidez é expressa em g de ácido cítrico/100 g de amostra de sumo e calculada de acordo com a equação 1 .

$$
\% \text { acidez }=6,4 V_{1} N_{\mathrm{NaOH}} / A \quad \text { equação } 1
$$

onde: $V_{l}$ é o volume de $\mathrm{NaOH}$ gasto até se atingir $\mathrm{pH}=8,2, \mathrm{~A}$ é a massa da amostra e $N_{N a O H}$ é a normalidade da solução de hidróxido de sódio aferida.

Determinação da cor: 
A determinação da cor foi efectuada no colorímetro Minolta CT-310 (Japão). Foi utilizado o sistema de CIE-Lab para a caracterização da cor, o qual faz uso das coordenadas rectangulares $\mathbf{L}^{*}$, $\mathbf{a} * \mathbf{e} \mathbf{b}^{*} . \mathbf{L}$ * representa a luminosidade e varia entre $\mathrm{L}=0$, a que corresponde o preto, e $\mathrm{L}=100$ a que corresponde o branco. $\mathbf{a}^{*}$ representa tons de verde quando os seus valores são negativos e tons de vermelho quando toma valores positivos. b* representa tons de azul quando os seus valores são negativos e tons de amarelo quando toma valores positivos.

Análises microbiológicas:

A validação do processo esterilização foi levada a cabo pela realização de análises microbiológicas antes e depois desta etapa. Os sumos foram avaliados microbiologicamente no que respeita à presença de mesófilos, termófilos e aos Clostridium sulfito-reductores. A determinação qualitativa da presença de mesófilos e termófilos consistiu na colocação dos frascos de sumo numa estufa, durante 72 horas, a $55^{\circ} \mathrm{C}$, e posterior observação do possível abaulamento da tampa. A determinação quantitativa de esporos de Clostridium sulfito-redutores foi efectuada pelo cultivo em placa no meio (Reinforced Clostridial Médium, Scharlau).

\section{Apresentação e discussão de resultados}

Rendimento:

O rendimento global do processo de fabrico de sumo de cenoura é relativamente baixo (cerca de 45\%). Este valor está de acordo com o rendimento de 50\% em sumo de cenoura obtido por Chen et al. (1996). Durante o processo de fabrico a operação que apresenta o rendimento mais baixo é a prensagem (Figura 2) com rendimentos que não chegam a atingir os $50 \%$. Nesta perspectiva a optimização do processo global passa pelo aumento do rendimento individual desta etapa. Com esse objectivo foram testados vários tempos de escaldão (60s, 90s, 120s e 150s).

Pela observação da Figura 2 é possível verificar que o aumento do tempo de escaldão influencia directamente a operação que pretendemos optimizar de uma forma negativa, não provocando grandes alterações na etapa de trituração. Nesta perspectiva o rendimento global do processo sofre uma nítida redução resultado do que se verifica na operação de prensagem. Hamatschek e Gunnewig (1994) referem rendimentos de prensagem de 75-80\%. A diferença verificada entre os nossos resultados pode estar relacionada com o tipo de prensagem efectuada, que é bastante rudimentar no nosso caso.

A optimização da etapa de prensagem passou pela adição de enzimas durante a operação prévia de trituração. As enzimas testadas foram a pectinase, a $\alpha$-amilase e a celulase. Simultaneamente à utilização destas enzimas foi também avaliada a influência dos diferentes 
tempos de escaldão no rendimento, verificando-se o mesmo comportamento descrito anteriormente e que se traduz numa diminuição do rendimento na operação de prensagem com o aumento do tempo de escaldão.

Figura 2 - Rendimento individual das operações e rendimento global do processo para diferentes tempos de escaldão.

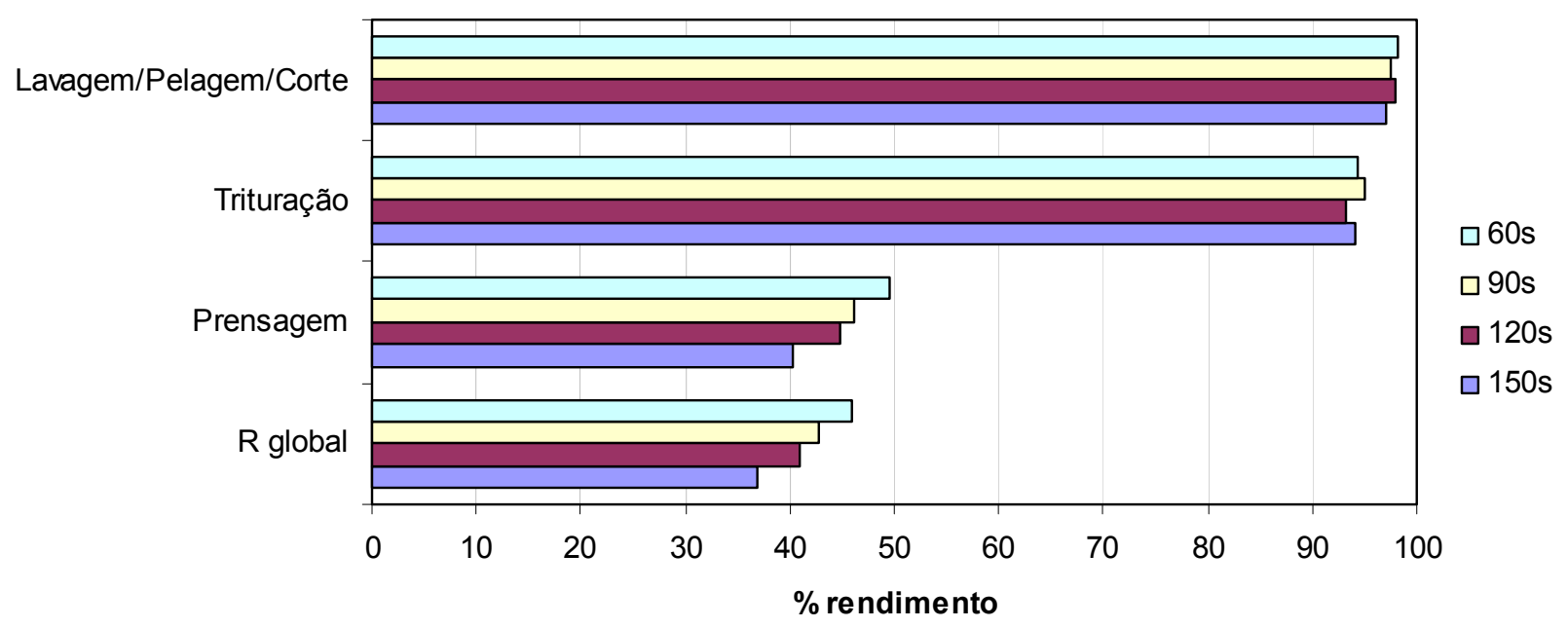

Relativamente aos rendimentos globais do processo obtidos pela utilização das enzimas, estes são significativamente superiores para todas as enzimas testadas (Figura 3). Este aumento no rendimento global é devido essencialmente ao aumento do rendimento da etapa de prensagem. A utilização da pectinase proporcionou o melhor rendimento global, aproximadamente $20 \%$ superior ao atingido no caso da não adição de enzimas. Os estudos de Anderson e Clydescale (1980) revelam que pequenos períodos de escaldão não afectam significativamente as propriedades das fibras, mas influenciam a estrutura das pectinas que são extremamente sensíveis à destruição térmica. As transformações verificadas com as pectinas conduzem ao aumento da fracção solúvel nos sumos e daí o rendimento em sumo ser o mais elevado para o caso do uso da enzima pectinase. Já o uso da celulase não se revela tão atractivo porque efectivamente a celulose está em menor concentração na composição da cenoura (Tabela 1). Uma forma de aumentar ainda mais o rendimento global do processo seria a utilização de preparações enzimáticas que actuassem simultaneamente nos diversos componentes da matéria-prima (pectina, fibras e amido). Zadernowski et al. (2003) consegue aumentar o rendimento em sumo até valores no intervalo (48-86\%) com a utilização da preparação enzimática Pectinex Ultra-SPL, e conclui que o método de trituração também é determinante para a obtenção destes valores.

O tratamento enzimático destrói parcialmente as paredes celulares, especialmente a estrutura das pectinas provocando a degradação de componentes de elevado peso molecular. Este fenómeno é 
responsável pela diminuição da viscosidade da polpa, proporcionando uma maior separação entre as fases sólida e líquida.

Figura 3 - Rendimento global do processo com a utilização de diferentes enzimas, para os tempos de escaldão de 60 s, 90 s, 120 s e 150 s.

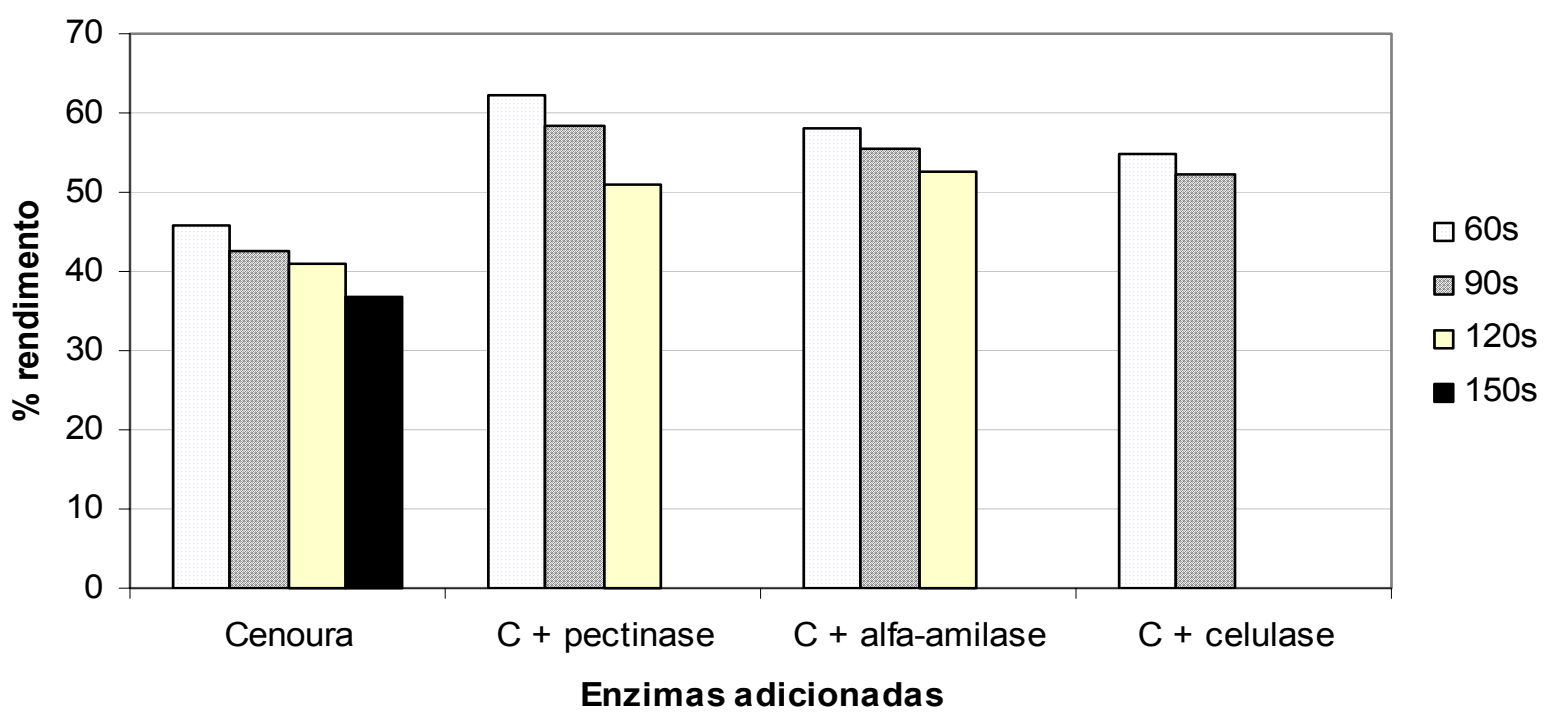

Sólidos Solúveis:

Podemos verificar que a quantidade de sólidos solúveis presentes nos sumos obtidos praticamente não depende do tempo de escaldão (Figura 4). O factor que influencia este parâmetro é o uso das diferentes enzimas. Tanto a utilização da pectinase como da $\alpha$-amilase não se revelou muito vantajosa neste estudo uma vez que a sua incorporação pouco contribui para um aumento no teor de sólidos solúveis no sumo de cenoura. Já a celulase proporcionou um aumento de $4{ }^{\circ}$ Brix relativamente à situação padrão. Este facto pode dever-se à elevada percentagem de fibra presente na cenoura $(1,01-2,44 \%)$, que ao ser degradada pela enzima celulase, contribui para um aumento significativo na concentração de sólidos solúveis. 
Figura 4 - Conteúdo em sólidos solúveis ( ${ }^{\circ}$ Brix) dos sumos de cenoura com a utilização de diferentes enzimas, para os tempos de escaldão de $60 \mathrm{~s}, 90 \mathrm{~s}, 120 \mathrm{~s}$ e $150 \mathrm{~s}$.

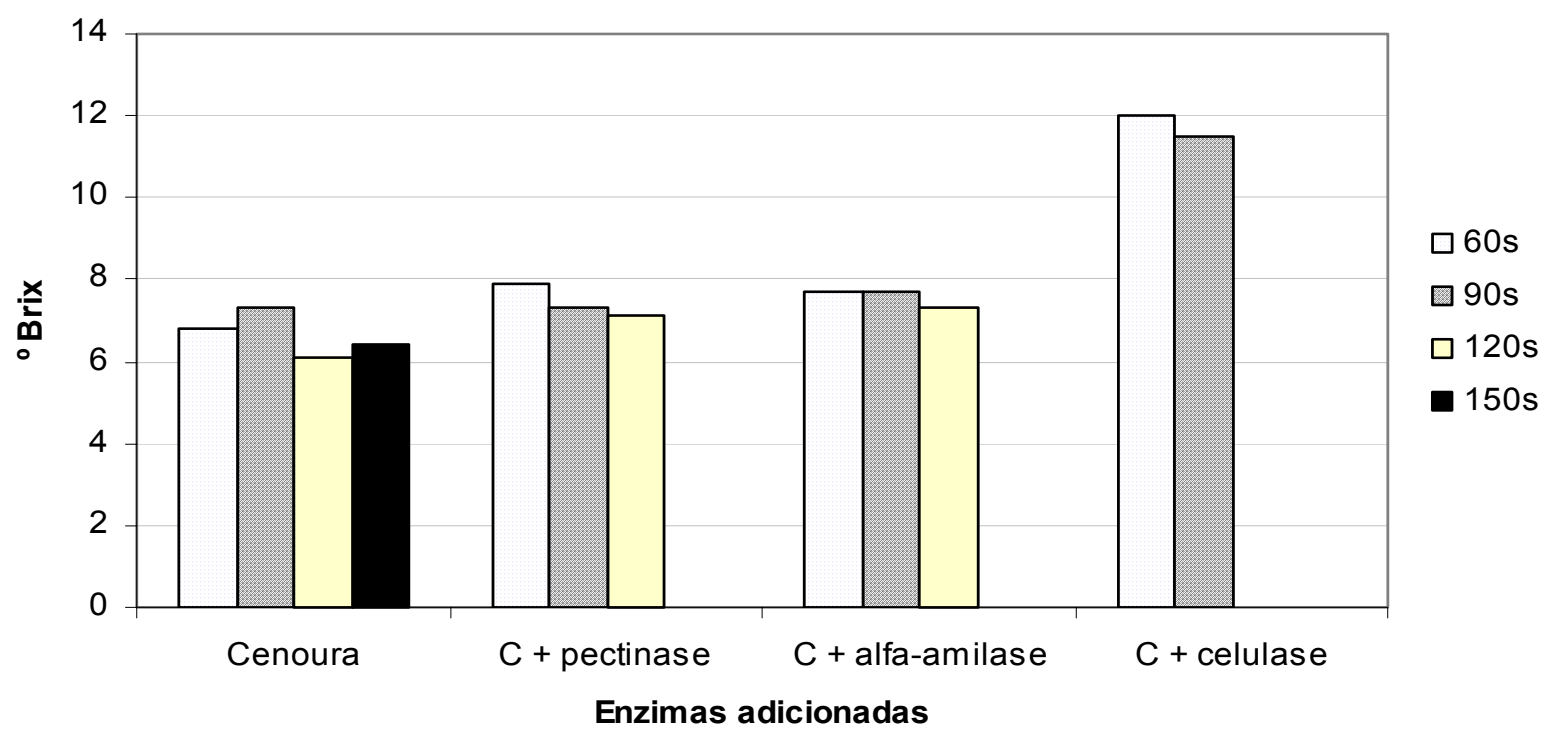

Acidez titulável e pH:

A adição de enzimas proporciona um aumento da acidez titulável dos sumos de cenoura (Figura 5). Enquanto que para o caso da utilização de pectinase a acidez atinge valores médios de $0,035 \%$, com a utilização de celulase verificamos uma acidez de 0,055 \%. Obviamente o aumento da acidez titulável proporciona uma diminuição do valor de pH (Figura 6).

Tanto a enzima pectinase como a enzima celulase têm o seu óptimo de actividade para $\mathrm{pH}$ entre 4,8 e 5, ou seja, o ambiente ácido beneficia a actuação destas enzimas. No sumo de cenoura o pH verificado encontra-se entre 6,5 e 6,7 e está mais próximo destes valores, daí a actuação bastante favorável da celulase. Já para a $\alpha$-amilase o seu pH óptimo situa-se próximo de 8 . Esta situação pode justificar a baixa actividade desta enzima, uma vez que tanto os sólidos solúveis como o rendimento do processo não saem muito valorizados pela sua utilização. 
Figura 5 - \% Acidez (g de ácido cítrico/ g de solução) dos sumos de cenoura, com a utilização de diferentes enzimas, para os tempos de escaldão de $60 \mathrm{~s}, 90 \mathrm{~s}, 120 \mathrm{~s}$ e $150 \mathrm{~s}$.

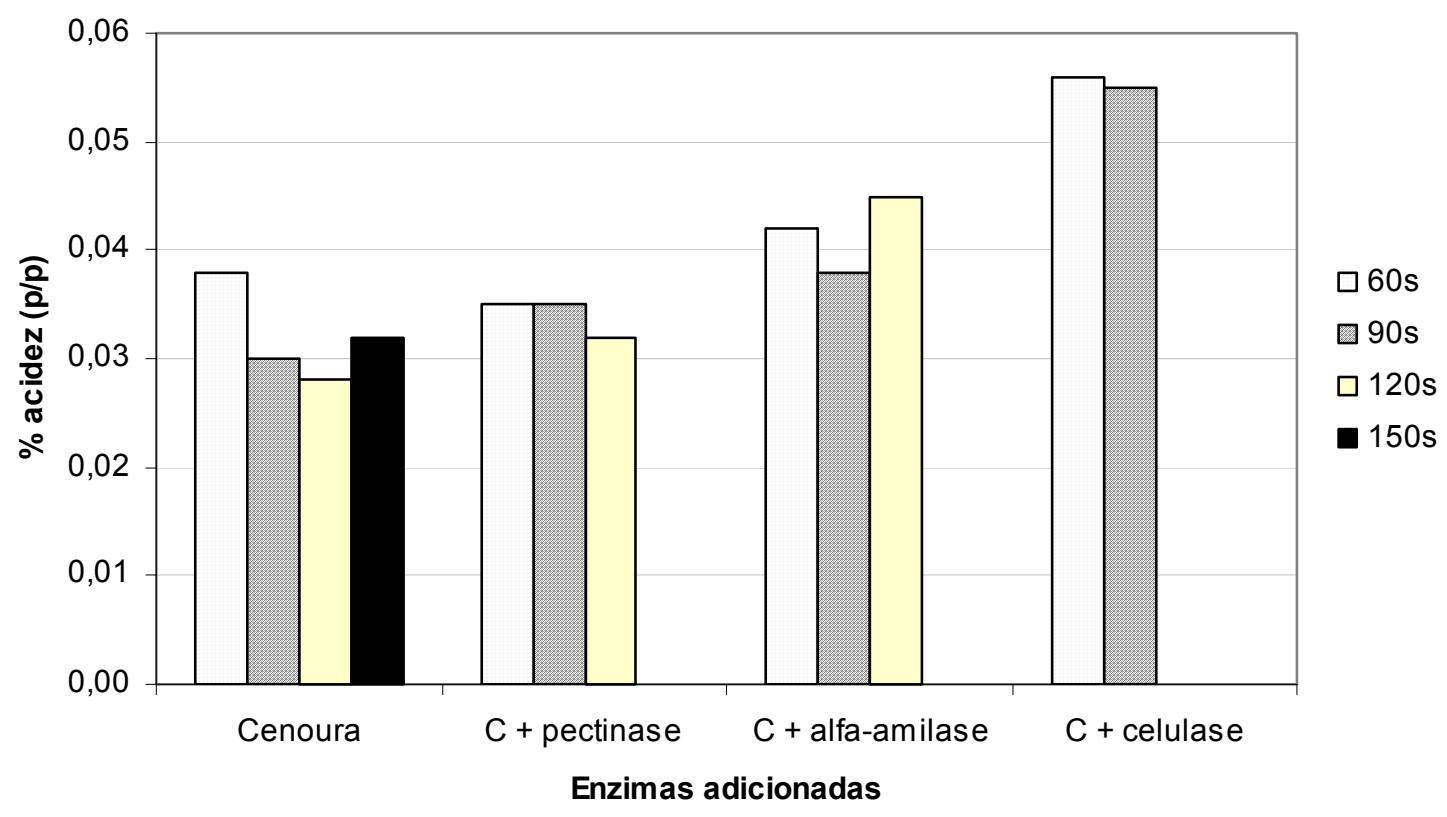

A acidez de 0,055\%, embora mais elevada para o caso do uso da pectinase, ainda não é de forma alguma a desejada para poder caracterizar o sumo de cenoura como um alimento de $\mathrm{pH}$ ácido $(\mathrm{pH}<4,2)$ e assim poder estabilizar microbiologicamente o sumo através de um tratamento térmico de pasteurização, aplicando temperaturas mais moderados quando comparadas com as exigidas para proceder a um tratamento de esterilização.

Figura 6 - pH dos sumos de cenoura com a utilização de diferentes enzimas, para os tempos de escaldão de $60 \mathrm{~s}, 90 \mathrm{~s}, 120 \mathrm{~s}$ e $150 \mathrm{~s}$.

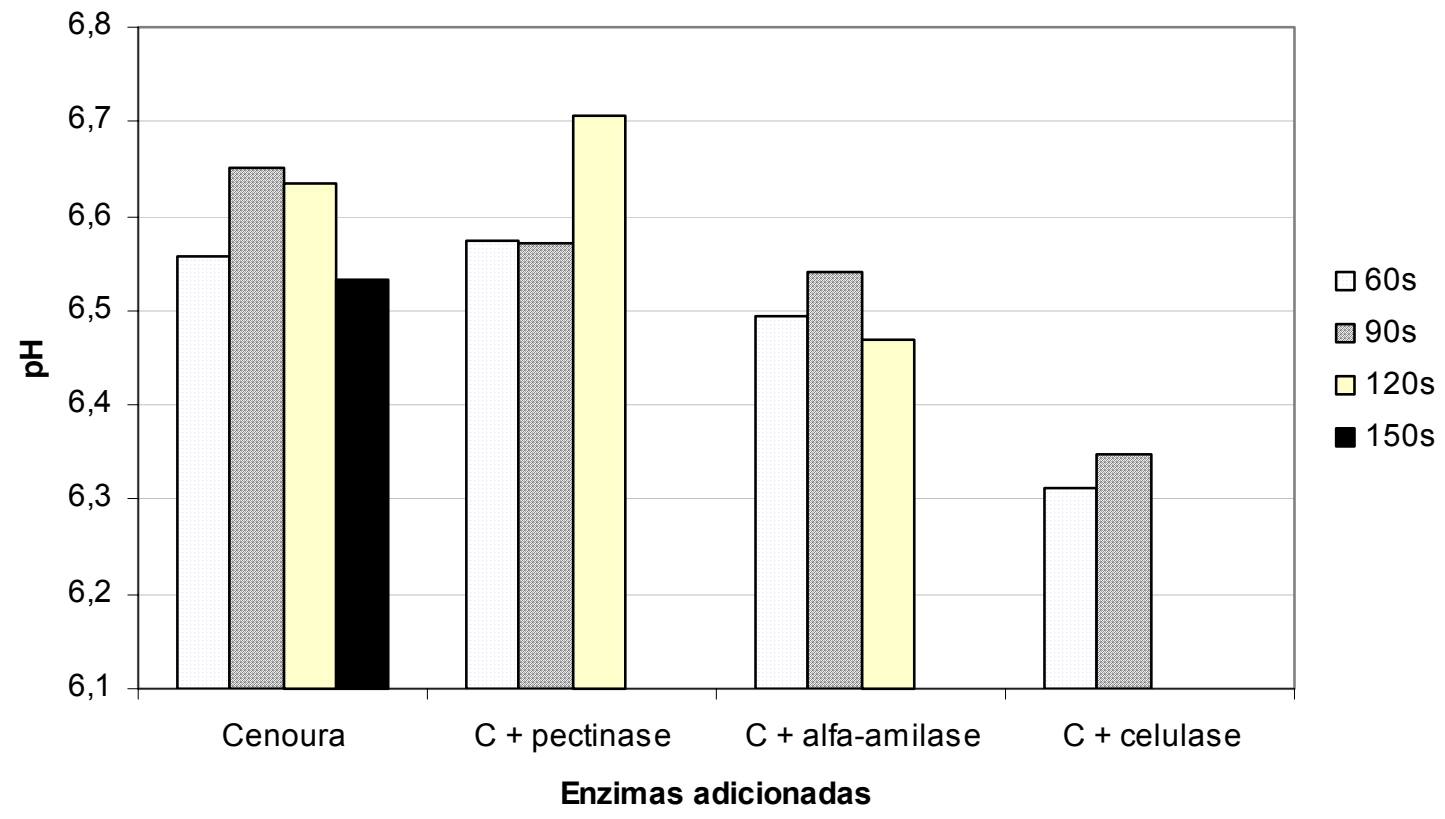


O tempo de escaldão praticamente não influencia estes dois parâmetros, uma vez que não existe uma tendência clara quando se aumenta este factor.

Cor:

A cor é um atributo importante no sumo de cenoura e varia devido à influência que as drásticas condições de esterilização podem provocar nos carotenoides. De forma geral a tonalidade amarela ( $b^{*}$ positivo) é a que domina no sumo de cenoura devido à presença significativa de $\beta$ caroteno neste sumo. Os parâmetros da cor $\left(\mathrm{L}^{*} \mathrm{a}^{*} \mathrm{~b}^{*}\right)$ não sofrem variações evidentes com a utilização de enzimas durante o processo de extracção do sumo (Tabela 2). Tal poderá estar relacionado com o facto da função enzimática ser a degradação dos polissacarídeos (pectinas, amido e celulose) presentes na matéria-prima, não afectando por sua vez a composição do sumo em termos de pigmentos (nomeadamente carotenoides).

No entanto, analisando a tabela 2 , enquanto que no teste sem a utilização de enzimas a variação de $L^{*}, a^{*}$ e $b^{*}$ quase não se verifica com o aumento do tempo de escaldão, isto já não acontece nos casos onde estas foram usadas. Nos ensaios com a utilização de enzimas já se verificam variações mais significativas nos parâmetros da cor para tempos de escaldão semelhantes.

Tabela 2 - Parâmetros L*, a* e b* dos sumos de cenoura com a utilização de diferentes enzimas, para os tempos de escaldão de 60s, 90 s, 120 s.

\begin{tabular}{ccccc}
\hline $\begin{array}{c}\text { Tempo de } \\
\text { escaldão (s) }\end{array}$ & $\begin{array}{c}\text { S cenoura } \\
\mathbf{L}^{*} \mathbf{a}^{*} \mathbf{b}^{*}\end{array}$ & $\begin{array}{c}\mathbf{S}+\text { pectinase } \\
\mathbf{L}^{*} \mathbf{a}^{*} \mathbf{b}^{*}\end{array}$ & $\begin{array}{c}\mathbf{S}+\alpha \text {-amilase } \\
\mathbf{L}^{*} \mathbf{a}^{*} \mathbf{b}^{*}\end{array}$ & $\begin{array}{c}\mathbf{S}+\text { celulase } \\
\mathbf{L}^{*} \mathbf{a}^{*} \mathbf{b}^{*}\end{array}$ \\
\hline $\mathbf{6 0}$ & $42,1 / 5,6 / 38,2$ & $42,1 / 6,7 / 34,7$ & $44,1 / 8,6 / 38,2$ & $41,4 / 6,5 / 34,7$ \\
$\mathbf{9 0}$ & $42,1 / 5,5 / 38,0$ & $44,0 / 5,8 / 37,9$ & $43,5 / 7,7 / 39,0$ & $37,7 / 5,4 / 33,2$ \\
$\mathbf{1 2 0}$ & $42,3 / 5,5 / 37,7$ & $46,4 / 8,2 / 44,5$ & $42,7 / 6,8 / 37,5$ & \\
\hline
\end{tabular}

Comparação das características do sumo produzido com sumos comerciais:

Pretendeu-se comparar as características físico-químicas ( ${ }^{\circ} \mathrm{Brix}, \mathrm{pH}$ e \% acidez) do sumo obtido nas instalações da oficina tecnológica de produtos horto-frutícolas de ESAC, com as dos sumos disponíveis no mercado e que fazem menção à incorporação do sumo de cenoura na sua composição. O parâmetro sensorial avaliado entre os diferentes produtos foi apenas a cor.

A diferença na composição em sólidos solúveis avaliados no sumo produzido e nos sumos comerciais seleccionados é de apenas $2{ }^{\circ}$ Brix (Figura 7). O valor obtido para este parâmetro nos sumos comerciais testados é, em todos os casos, superior ao do sumo de cenoura produzido. Verifica-se também que os sumos que apresentam adição de limão apresentam os valores mais elevados. Uma das formas de aumentar o conteúdo em sólidos solúveis pode passar pela utilização 
de enzimas durante o processamento do sumo. De acordo com os resultados obtidos previamente é possível atingir valores na ordem dos $12{ }^{\circ}$ Brix que por conseguinte ultrapassam os valores praticados no mercado actualmente. Assim poder-se-á aumentar o rendimento global do processo por diluição ou ter a vantagem económica do sumo produzido.

Figura 7 - Comparação das características físico-químicas ${ }^{\circ}$ Brix, $\mathrm{pH}$ e $\%$ acidez, do sumo de cenoura produzido e de sumos comerciais que apresentam sumo de cenoura na sua composição.
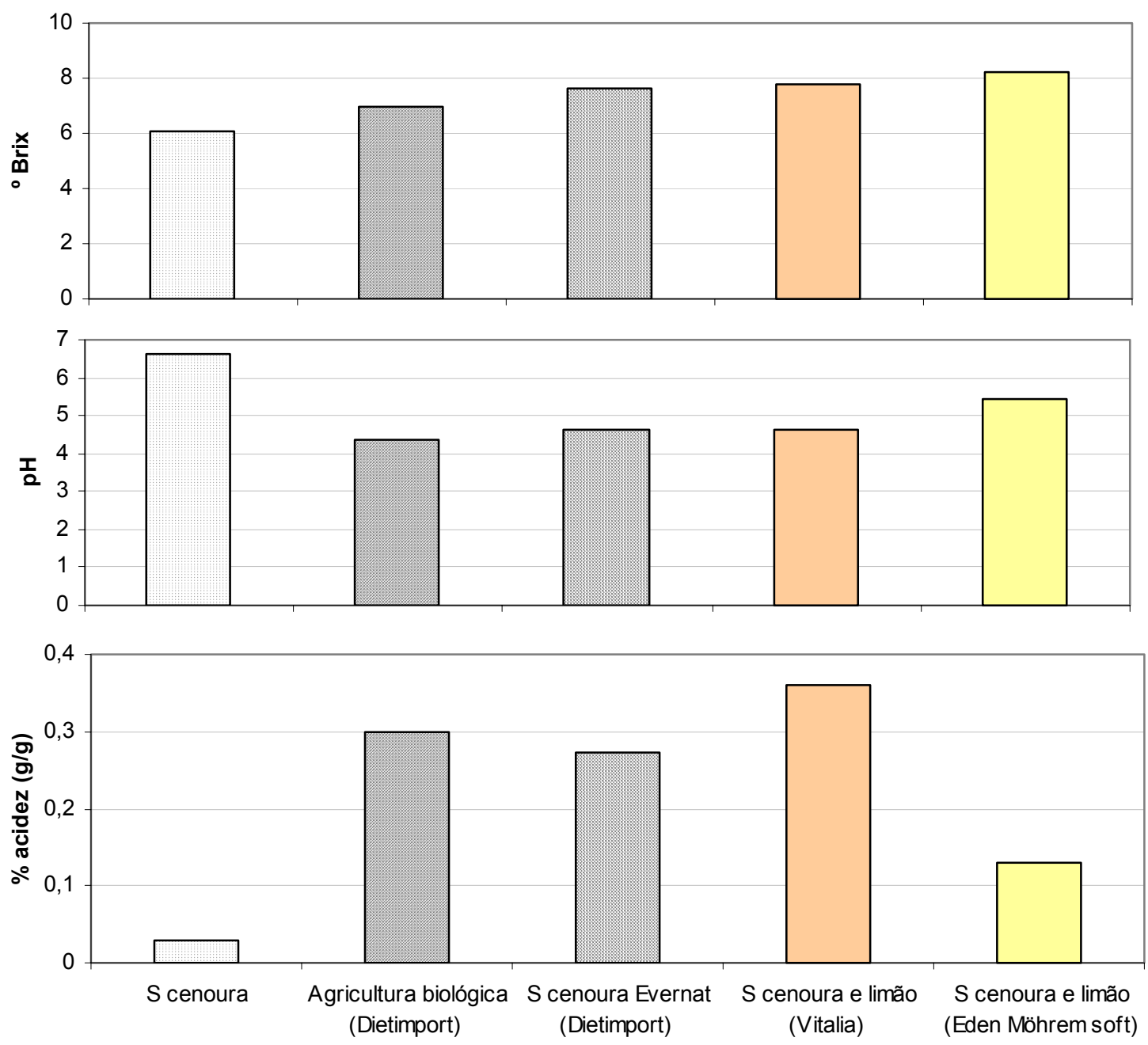

Da análise da Figura 7 é obvio que os sumos comerciais avaliados não contêm unicamente sumo de cenoura, sendo antes o resultado da mistura de sumos mais ácidos como é o caso do de limão ou então de aditivos que têm por função aumentar a acidez do produto final. Uma vez que o sumo de cenoura possui uma acidez muito baixa relativamente a outros sumos de fruta, a sua utilização na confecção de sumos permite um abaixamento significativo neste parâmetro, conferindo ao produto uma melhoria de sabor e um enriquecimento nas propriedades nutricionais que estão associadas à cenoura. 
Os resultados apresentados na Figura 8 mostram que o parâmetro $L^{*}$ e b*, responsáveis pelas cores branca e amarela, são muito semelhantes entre o sumo produzido e os sumos comerciais. No entanto, a contribuição do tom vermelho (a*) é significativamente menor no sumo produzido. Esta diferença pode ser devida à possível adição de outros compostos aos sumos comerciais. Os sumos que contêm limão na sua composição são os que apresentam o parâmetro a* mais próximo do sumo obtido. No caso do uso de enzimas durante o processamento, o tom vermelho é favorecido (Tabela 2).

Figura 8 - Comparação dos parâmetros $\mathrm{L}^{*}, \mathrm{a}^{*}$ e b* do sumo de cenoura produzido e de sumos comerciais que apresentam sumo de cenoura na sua composição.

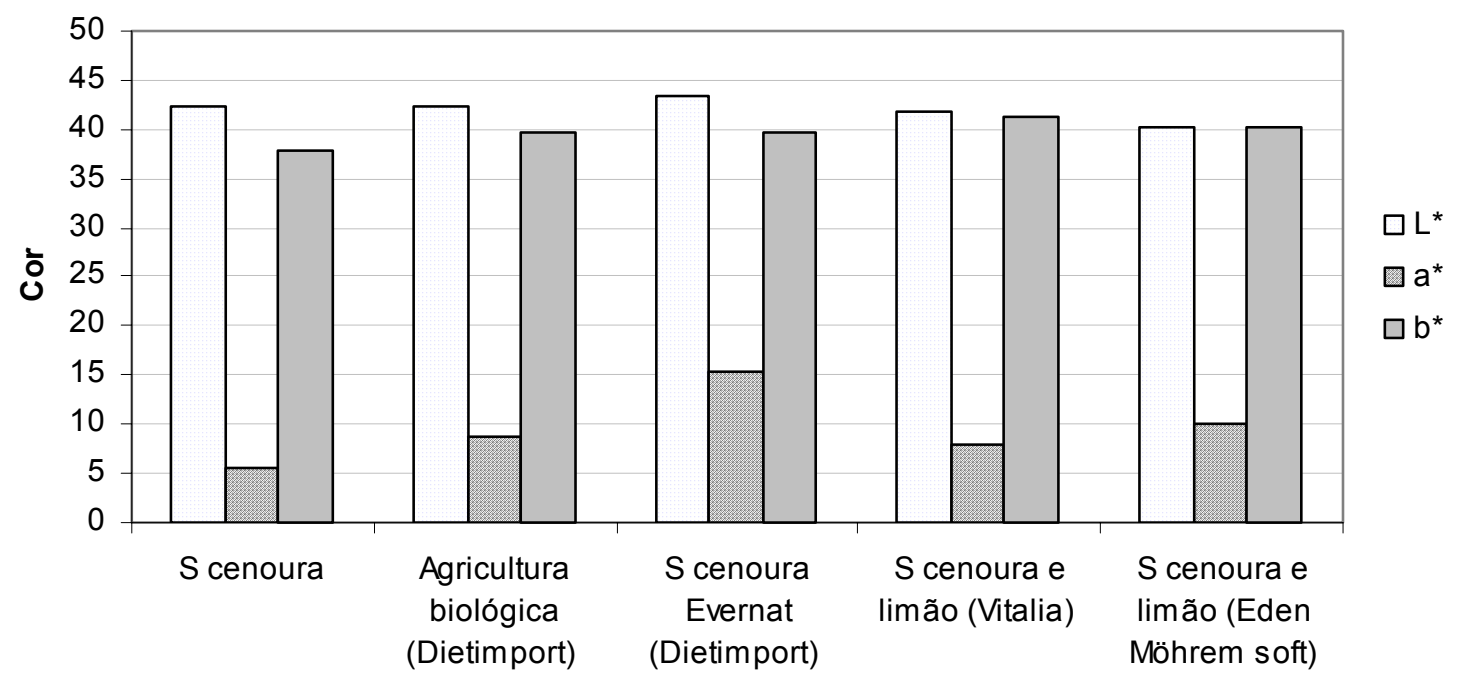

Estabilidade microbiológica do sumo:

Uma vez que o $\mathrm{pH}$ do sumo de cenoura produzido apresenta valores muito acima de 4,2, a sua estabilização microbiológica via processo térmico, só poderá ser alcançada utilizando temperaturas superiores a $100{ }^{\circ} \mathrm{C}$. O processo de esterilização foi realizado em autoclave à temperatura de $121,1{ }^{\circ} \mathrm{C}$, durante 30 minutos. Este processo foi acompanhado através do registo da temperatura no interior das embalagens de vidro com capacidade para $200 \mathrm{~mL}$ de sumo. $\mathrm{O}$ valor de $\mathrm{F}_{0}$ obtido foi 14. Estas condições de esterilização asseguraram a estabilidade microbiológica do sumo tal como se pode concluir pelos resultados da Tabela 3.

Os valores de $\mathrm{F}_{0}$ praticados estão acima dos necessários para garantir a esterilização comercial do sumo $\left(\mathrm{F}_{0}=5\right)$ (Reiter et al., 2003), podendo influenciar negativamente a sua qualidade organoléptica e nutricional, uma vez que favorecem a ocorrência de reacções indesejadas durante o excessivo tempo de esterilização. Este processo poderá ser optimizado para que, garantindo a esterilização do produto obtido, o tempo utilizado possa ser minimizado. Pretende-se desta forma 
diminuir os efeitos negativos que os processos térmicos provocam nos elementos que contribuem para o elevado valor nutricional do sumo de cenoura.

Tabela 3 - Resultados microbiológicos depois da etapa de esterilização, para os microrganismos termófilos, mesófilos e Clostridium sulfito-redutores.

\begin{tabular}{lll}
\hline \multirow{2}{*}{ Microrganismos } & \multicolumn{2}{c}{ Resultados microbiológicos } \\
\cline { 2 - 3 } & Antes da esterilização & Depois da esterilização \\
\hline Mesófilos & Presença & Não se observou abaulamento das tampas dos frascos \\
\hline Termófilos & Presença & Não se observou abaulamento das tampas dos frascos \\
\hline Esporos de Clostridium & $>300 \times 10^{6} \mathrm{UFC} / \mathrm{mL}$ & Não se observou o desenvolvimento de colónias \\
sulfito redutores & & \\
\hline
\end{tabular}

\section{Conclusões}

O rendimento global do processo obtido para o sumo de cenoura produzido para um tempo de escaldão de $60 \mathrm{~s}$ e sem a adição de enzimas foi de $50 \%$, a operação que mais o penaliza é a prensagem, com rendimentos operacionais na ordem dos 40-50\%. Com o intuito de se optimizarem estes rendimentos foram testados diferentes tempos de escaldão e a utilização de enzimas durante o processamento. O menor tempo de escaldão (60 s) beneficia o rendimento global do processo independentemente do tipo de enzima testada. A enzima pectinase é aquela que conduz a rendimentos globais de extracção do sumo de cenoura mais elevados, cerca de 15\% superiores aos obtidos para o caso da não utilização de enzimas. No entanto, já o ${ }^{\circ}$ Brix é maximizado quando a enzima utilizada é a celulase. Uma alternativa para conjugar estes dois efeitos será a utilização destas duas enzimas combinadas ou a sua utilização sequencial. A acidez titulável do sumo produzido é de $0,035 \%(\mathrm{p} / \mathrm{p})$ e aumenta até $0,055 \%(\mathrm{p} / \mathrm{p})$ com os tratamentos enzimáticos. No entanto, ainda não é suficiente para proporcionar estabilidade ao produto, de forma a evitar os processos térmicos de esterilização, em detrimento da pasteurização com condições de processamento mais suaves e menos prejudiciais para o produto, em termos funcionais. A cor não é significativamente afectada pelo tempo de escaldão quando não se utilizam enzimas, mas nos casos onde estas se empregam as variações já se conseguem identificar embora não sejam expressivas.

Da comparação do sumo produzido com sumos comerciais seleccionados podemos concluir que a acidez é inferior e consequentemente o $\mathrm{pH}$ é mais elevado. Tal facto pode ser devido à incorporação de outros sumos, nomeadamente o de limão ou compostos acidificantes com o objectivo de estabilizar os sumos comerciais. O processo de esterilização utilizado foi eficaz garantindo a estabilidade microbiológica do produto. A sua optimização deve ser efectuada com o intuito de minimizar o tempo excessivo ao qual os compostos de elevado valor nutricional estão 
sujeitos, minimizando a sua degradação térmica.

\title{
5. Referências
}

ANDERSON, E.; CLYDESCALE, F. Effects of processing on the dietary fibber content of wheat bran, purred green beans and carrots. Journal of Food Science, v.45, p.1533-1537, 1980.

BOROWSKA, E.J.; ZADERNOWSKI, R.; SZAJDEK, A.; ZADERNOWSKI, A. Effects of carrots variety and processing on unpreserved carrot juice quality, Fruit Processing, v.1, p.22-27, 2006.

CHEN, H.; PENG, H.; CHEN, B. Stability of carotenoids and vitamins A during storage of carrots. Food Chemistry, v.57, n.4, p.497-503, 1996.

COULTATE, T.P. Alimentos - Química de sus components. Zaragoza: Editorial Acribia S.A, 1986.

HELBIG, J.; LAPERCHE, S. Production of colour -intensive and colour stable juice, Fruit Processing, v.2, p.324-347, 2001.

REITER, M.; STUPARÍC. M.; NEIDHART. S.; CARLE. R. The role of process in carrot juice cloud stability, Lebensm.-Wiss. U.-Technol., v.36, p.165-172, 2003.

SUN, Y.; WANG, Z.; WU, J.; CHEN, F.; LIAO, X.; HU, X. Optimising enzymatic maceration in pre-treatment of carrot juice concentrate by response surface methodology, International Journal of Food Science and Technology, v. 41(9), p.1082-1089, 2006.

USDA, National Nutrient Database for Standard Reference, Carrot juice canned, disponível em $\leq$ http:/www.nal.usda.gov/fnic/foodcomp/search/>, acesso em 14/12/2006.

VORA, H.; KYLE, W.; SMALL, D. Effect of enzymes treatment of carrots pulp on juice yield and quality, Food Australia, v.51(4), p.146-147, 1999.

ZADERNOWSKI, R.; BOROWSKA, J.; KOWALSA, M.; BUDREWICZ, G.; SZAJDEK, A., Quality of carrots juice as conditioned by raw material and technology, Science and Research, p.183-192, 2003.

\begin{abstract}
The consumption of fruit juices has recently increased due to its incorporation in the consumers diet, partly displacing regular fruit and soda beverages. The vitaminic and antioxidant characteristics of carrot juice led to its introduction in fruit juice formulations. The main problems in its utilization are the lower production yield and the chemical and microbiological stability.

The objective of this work was the optimization of the yield in carrot juice production. The factors tested were the branching time $(60,90,120,150 \mathrm{~s})$ and the addiction of enzymes (pectinase, $\alpha$ amilase and celulase) during the grinding process. We also evaluated the influence that the thermal processes had in $\mathrm{pH},{ }^{\circ} \mathrm{Brix}$, acidity and colour of the produced juice. Microbiological analyses for the commercial sterility evaluation of the bottled juice were also performed.

The increase in the blanching time prejudices the yield of the global process, mainly by decreasing the yield in the pressing operation. The use of enzymes favours the production yield. The pectinase was the more efficient because it allows an increase in yield of $20 \%$. The use of pectinase improves the soluble solids content $\left(12^{\circ}\right.$ Brix $)$ and the acidity $(0,055 \%(\mathrm{w} / \mathrm{w}))$. The microbiological stability was achieved with autoclave sterilization.
\end{abstract}

Key-words: carrot juice, yield, blanching, enzymatic treatment, sterilization. 


\section{Referências}

ANDERSON, E.; CLYDESCALE, F. Effects of processing on the dietary fibber content of wheat bran, purred green beans and carrots. Journal of Food Science, v.45, p.1533-1537, 1980.

BOROWSKA, E.J.; ZADERNOWSKI, R.; SZAJDEK, A.; ZADERNOWSKI, A. Effects of carrots variety and processing on unpreserved carrot juice quality, Fruit Processing, v.1, p.22-27, 2006.

CHEN, H.; PENG, H.; CHEN, B. Stability of carotenoids and vitamins A during storage of carrots. Food Chemistry, v.57, n.4, p.497-503, 1996.

COUlTATE, T.P. Alimentos - Química de sus components. Zaragoza: Editorial Acribia S.A, 1986.

HELBIG, J.; LAPERCHE, S. Production of colour -intensive and colour stable juice, Fruit Processing, v.2, p.324-347, 2001.

REITER, M.; STUPARÍC. M.; NEIDHART. S.; CARLE. R. The role of process in carrot juice cloud stability, Lebensm.-Wiss. U.-Technol., v.36, p.165-172, 2003.

SUN, Y.; WANG, Z.; WU, J.; CHEN, F.; LIAO, X.; HU, X. Optimising enzymatic maceration in pre-treatment of carrot juice concentrate by response surface methodology, International Journal of Food Science and Technology, v. 41(9), p.1082-1089, 2006.

USDA, National Nutrient Database for Standard Reference, Carrot juice canned, disponível em $\leq$ http://www.nal.usda.gov/fnic/foodcomp/search/>, acesso em 14/12/2006.

VORA, H.; KYLE, W.; SMALL, D. Effect of enzymes treatment of carrots pulp on juice yield and quality, Food Australia, v.51(4), p.146-147, 1999.

ZADERNOWSKI, R.; BOROWSKA, J.; KOWALSA, M.; BUDREWICZ, G.; SZAJDEK, A., Quality of carrots juice as conditioned by raw material and technology, Science and Research, p.183-192, 2003.

\section{Inserir aqui dados completos de TODOS os autores:}

Nome completo: Luis Santiago Calvo Fariña

Filiação institucional: Escuela Técnica Superior de Ingenierías Agrarias de Palencia

Departamento: Industrias Agrarias y Alimentarias

Função ou cargo ocupado: Estudante

Endereço completo para correspondência (bairro, cidade, estado, país e CEP): c/ Kilimanjaro 5, $5^{\circ} \mathrm{A}$ cp 47013 Valladolid (España)

Telefones para contato: 34669124077

e-mail:demiurgo1977@hotmail.com

Nome completo: Ivo Manuel Mira Abreu Rodrigues

Filiação institucional: Escola Superior Agrária de Coimbra - Instituto Politécnico de Coimbra

Departamento: Departamento de Ciências e Tecnologia Alimentar

Função ou cargo ocupado: Docente

Endereço completo para correspondência (bairro, cidade, estado, país e CEP): Bencanta, 3040-316

Coimbra, Portugal

Telefones para contato: +351239802 940: +351936401452

e-mail:ivorod@esac.pt 
Nome completo: Marta Helena Fernandes Henriques

Filiação institucional: Escola Superior Agrária de Coimbra - Instituto Politécnico de Coimbra

Departamento: Departamento de Ciências e Tecnologia Alimentar

Função ou cargo ocupado: Docente

Endereço completo para correspondência (bairro, cidade, estado, país e CEP): Bencanta, 3040-316

Coimbra, Portugal

Telefones para contato: +351239802 940: +351918 836242

e-mail: mhenriques@esac.pt

Nome completo: Rui Saraiva

Filiação institucional: Escola Superior Agrária de Coimbra - Instituto Politécnico de Coimbra

Departamento: Departamento de Ciências e Tecnologia Alimentar

Função ou cargo ocupado: Docente

Endereço completo para correspondência (bairro, cidade, estado, país e CEP): Bencanta, 3040-316

Coimbra, Portugal

Telefones para contato: +351239802940

e-mail: rsaraiva@esac.pt 